\title{
Arterial Tortuosity Syndrome: An Ascorbate Compartmentalization Disorder?
}

\author{
Annekatrien Boel, ${ }^{1}$ Krisztina Veszelyi, ${ }^{2}$ Csilla E. Németh, ${ }^{3}$ Aude Beyens, \\ Andy Willaert, ${ }^{1}$ Paul Coucke, ${ }^{1}$ Bert Callewaert, ${ }^{1, *}$ and Éva Margittai ${ }^{2, *}$
}

\begin{abstract}
Significance: Cardiovascular disorders are the most important cause of morbidity and mortality in the Western world. Monogenic developmental disorders of the heart and vessels are highly valuable to study the physiological and pathological processes in cardiovascular system homeostasis. The arterial tortuosity syndrome (ATS) is a rare, autosomal recessive connective tissue disorder showing lengthening, tortuosity, and stenosis of the large arteries, with a propensity for aneurysm formation. In histopathology, it associates with fragmentation and disorganization of elastic fibers in several tissues, including the arterial wall. ATS is caused by pathogenic variants in SLC2A10 encoding the facilitative glucose transporter (GLUT) 10.

Critical Issues: Although several hypotheses have been forwarded, the molecular mechanisms linking disrupted GLUT10 activity with arterial malformations are largely unknown.

Recent Advances: The vascular and systemic manifestations and natural history of ATS patients have been largely delineated. GLUT10 was identified as an intracellular transporter of dehydroascorbic acid, which contributes to collagen and elastin cross-linking in the endoplasmic reticulum, redox homeostasis in the mitochondria, and global and gene-specific methylation/hydroxymethylation affecting epigenetic regulation in the nucleus. We revise here the current knowledge on ATS and the role of GLUT10 within the compartmentalization of ascorbate in physiological and diseased states.

Future Directions: Centralization of clinical, treatment, and outcome data will enable better management for ATS patients. Establishment of representative animal disease models could facilitate the study of pathomechanisms underlying ATS. This might be relevant for other forms of vascular dysplasia, such as isolated aneurysm formation, hypertensive vasculopathy, and neovascularization. Antioxid. Redox Signal. 00, 000-000.
\end{abstract}

Keywords: arterial tortuosity syndrome, ascorbate, GLUT10, compartmentalization

\section{Introduction}

$\mathbf{I}_{\mathrm{a}}^{\mathrm{s}}$ $\mathrm{N}$ SPECIES HAVING LOST the ability to biosynthesize ascorbic acid (AA), such as Homo sapiens, AA sparing is of utmost importance $(7,57)$. AA-dependent reactions are presumably found in all subcellular compartments of animal cells. Aberrant subcellular compartmentalization of AA has been implicated in both inherited and acquired human diseases, including Werner syndrome (58), cancer (11), and subcellular scurvy $(100,101)$.
AA has a ubiquitous antioxidant function and acts especially in organelles characterized by oxidative metabolic reactions, such as mitochondria, peroxisomes, and the endoplasmic reticulum (ER). Beyond its general antioxidant properties, AA is required for proper functioning of several enzymes, including AA-dependent mono- and dioxygenases $(54,56,74)$ present in various subcellular compartments; for example, hypoxia-inducible factor prolyl hydroxylases in the cytoplasm, collagen prolyl/lysyl hydroxylases in the ER lumen $(65,88)$, dopamine $\beta$-monooxygenase

\footnotetext{
${ }^{1}$ Department of Biomolecular Medicine, Center for Medical Genetics Ghent, Ghent University, Ghent, Belgium.

${ }^{2}$ Institute of Clinical Experimental Research and ${ }^{3}$ Department of Medical Chemistry, Molecular Biology, and Pathobiochemistry, Semmelweis University, Budapest, Hungary.

*These authors are joint last authors.
} 
and peptidylglycine $\alpha$-hydroxylating monooxygenase in chromaffin granules, synaptic and secretory vesicles (27), and histone and DNA demethylases in the nucleoplasm.

Two families of membrane transporters, namely sodiumdependent vitamin C transporters (SVCTs) and facilitative glucose transporters (GLUTs), accommodate for cellular accumulation and the subcellular distribution of AA. Vitamin $\mathrm{C}$ can be transported in both a reduced form (AA) and an oxidized form (dehydroascorbic acid [DHA]). The mechanisms involved are summarized in Figure 1.

SVCTs are highly specific active transporters of anionic AA (13). SVCT1 (SLC23A1) and SVCT2 (SLC23A2) specifically carry AA across membranes otherwise impermeable for the anion. SVCT1 has a high capacity, but low affinity, for AA and is primarily involved in intestinal absorption (13) and renal reabsorption to reduce urinary loss of AA $(59,81)$. SVCT2 is a very high-affinity lower-capacity transporter, which is more ubiquitous and responsible for transferring AA into a variety of cells and tissues. This transporter is also present in intracellular membranes, including the inner mitochondrial membrane $(5,64)$. Thus, SVCT1 enables AA accumulation at the level of the whole organism, while SVCT2 ensures the AA supply of each cell and some of their intracellular compartments.

The oxidized form of vitamin C, DHA, can further be transported by several GLUT family members (SLC2, solute carrier protein 2) via facilitated diffusion [reviewed in (63)]. Under physiological conditions, DHA transport is thought to be less significant since DHA is present at low concentrations in extra- and intracellular compartments due to its unstable nature. DHA is rapidly reduced to AA by thiol-dependent mechanisms on the trans side of the membrane at the expense of nicotinamide adenine dinucleotide phosphate and preserves its antiscorbutic properties. However, GLUT-dependent DHA transport may increase substantially under oxidative stress or by oxidase activity in the vicinity of the membrane (68). GLUT1-4, 8, and 10 are the best-documented, facilitative DHA transporters, which either associate with the plasma membrane or preferentially localize to specific organelles (6).

Overall, the concerted action of both the SVCT and GLUT families results in the intracellular accumulation of tremendous amounts of AA (intracellular: $1-10 \mathrm{~m} M$ versus blood plasma: $50-100 \mu M$ ) and in its distribution between organelles (Fig. 1).
Nevertheless, the intracellular distribution of vitamin $\mathrm{C}$ and distribution and functioning of AA/DHA transporters remain important, yet incompletely resolved, mechanisms [reviewed in (6)] that are difficult to assess in the absence of in vivo applicable tools for measurement of AA/DHA concentrations in subcellular compartments. A recently proposed approach used high-resolution immunoelectron microscopy and immunogold labeling of AA (99) and demonstrated the presence of AA in organelles of plants at different concentrations that may change under (patho)physiological conditions $(45,84)$.

Genetic diseases associated with GLUTs are very rare, emphasizing their vital importance and robustness of the family. Mutations in $S L C 2 A 1, S L C 2 A 2$, and $S L C 2 A 10$ are, respectively, associated with neurological disorders with variable intellectual disability and epilepsy [OMIM 606777, (83)], Fanconi-Bickel syndrome [a tubulopathy with intellectual disability, OMIM 227810, (79, 89)], and arterial tortuosity syndrome [ATS, OMIM 208050, (26)]. ATS is a rare congenital disorder belonging to the group of cutis laxa syndromes, associating with arterial tortuosity and aneurysm formation (91). The molecular link between mutations in the facilitative glucose transporter GLUT10 (encoded by SLC2A10) and the observed phenotype remains obscure. Hence, it is not surprising that several hypotheses have been forwarded to explain the pathomechanism. We critically review the existing suggestions and draw up a unifying hypothesis.

\section{Clinical Manifestations in ATS}

\section{Initial presentation and molecular diagnosis}

Most patients present with a cardiac murmur or reduced femoral pulsation. Less frequently, neonatal respiratory failure due to infant respiratory distress syndrome, pulmonary hypertension, or a diaphragmatic hernia may be the initial presentation. A rare initial hint to the diagnosis is a remarkably stretchable or lax skin. Workup with echocardiography reveals kinking of the aortic arch, for which more extensive vascular imaging with magnetic resonance angiography, computed tomography, or percutaneous angiography is initiated. Upon observation of widespread tortuosity of the aorta and middle-sized arteries, genetic analysis is carried out. The identification of biallelic pathogenic variants in SLC2A10 confirms the diagnosis of ATS.

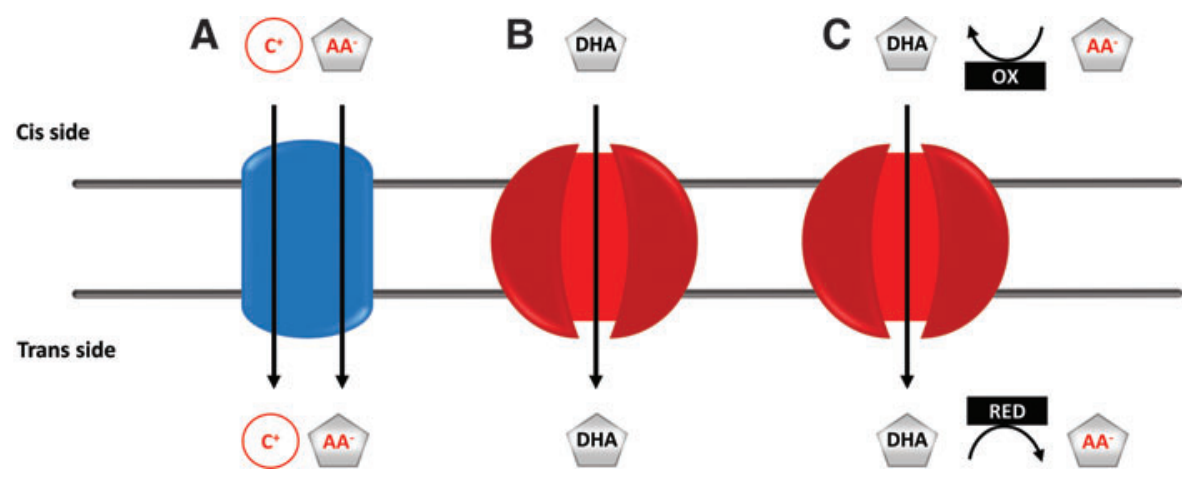

FIG. 1. Possible mechanisms of ascorbate transport through membranes. (A) Secondary active transport coupling the movement of cations $\left(\mathrm{C}^{+}\right)$down their gradient with the uphill transport of the ascorbate anion (AA ${ }^{-}$). (B) GLUTs enable facilitated diffusion of dehydroascorbic acid. (C) The transport of intracellular DHA, present at extremely low concentrations, can be promoted by an ascorbate oxidase on the cis and a DHA reductase on the trans side of the membrane. AA, ascorbic acid; DHA, dehydroascorbic acid; GLUT, glucose transporter; OX, oxidation; RED, reduction. Color images are available online. 
In view of the broad differential diagnosis, most of the patients undergo testing for a panel of genes relevant for arterial aneurysms and tortuosity or undergo targeted exome analysis for a panel of genes related to connective tissue disorders. Of note, a review of evidence for genes that should be included in diagnostic gene panels for heritable thoracic aortic disease does not withhold $S L C 2 A 10$ (75). Although assigned as a potentially diagnostic gene, evidence is currently limited in the context of heritable thoracic aortic diseases based on its association with a syndromic presentation (rather than isolated vascular disease) and the absence of an unequivocal risk for dissection. Hence, some diagnostic panels for heritable thoracic aortic diseases may not include $S L C 2 A 10$.

The spectrum of $S L C 2 A 10$ variants encompasses missense, nonsense, and splice-site mutations, besides large (exonic) and small deletions (4). So far, no genotype-phenotype correlation has been observed, impeding prognosis assessment and disease management by early genotyping $(9,14,16,77)$.

\section{Cardiovascular features and natural history}

Generalized tortuosity of the aorta and/or middle-sized arteries is invariably present, sporadically being associated with dilated or slightly tortuous large veins $(9,16,62)$. Aortic side branches, including the truncus brachiocephalicus and left subclavian artery, may show an aberrant implantation on the aorta (Fig. 2).

A slight majority of patients $(57 \%)$ have pulmonary artery stenosis, either of the truncus pulmonalis or the main or pe- ripheral pulmonary branches. Pulmonary hypertension is observed in some patients and may or may not be associated with pulmonary artery stenosis. About one-quarter of the patients have a stenosis of the aorta that may be focal (mostly at the isthmus aortae) or present as a long stenotic stretch or hypoplastic aorta. Other artery stenoses are less common $(\sim 15 \%)$, but may involve any middle-sized arteries, including the renal arteries. In addition, severe kinking of arteries may cause functional stenosis $(9,16)$.

Patients are at risk of developing aneurysms of the aortic root (commonly at the sinuses of Valsalva). Some patients have presented with aggressive aortic root dilatation before the age of 4 years, requiring urgent surgery. Others have shown slowly progressive aortic root dilatation in young adulthood. Nevertheless, no aortic dissections have been unequivocally recorded to date $(9,16)$. Mitral valve prolapse and cardiomyopathy have been reported (9). It is unclear if cardiomyopathy is due to secondary remodeling or a primary event (as in the related Marfan syndrome) (18).

Ischemic events $(9,16,19,33)$, including stroke, are a concern. Of note, initial reports have described organ infarctions as a cause of death in young children clinically diagnosed with ATS $(8,71,93)$, some of whom were confirmed molecularly afterward.

While initial mortality rates were reported up to $40 \%$ before the age of 4 (93), larger cohorts of patients with a molecularly confirmed diagnosis revealed a milder disease course $(9,16)$.
A
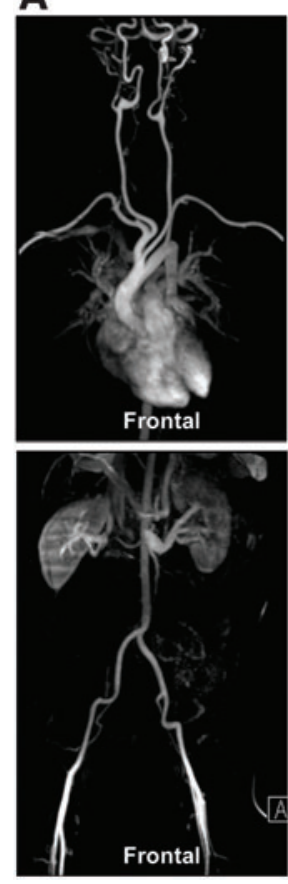

B
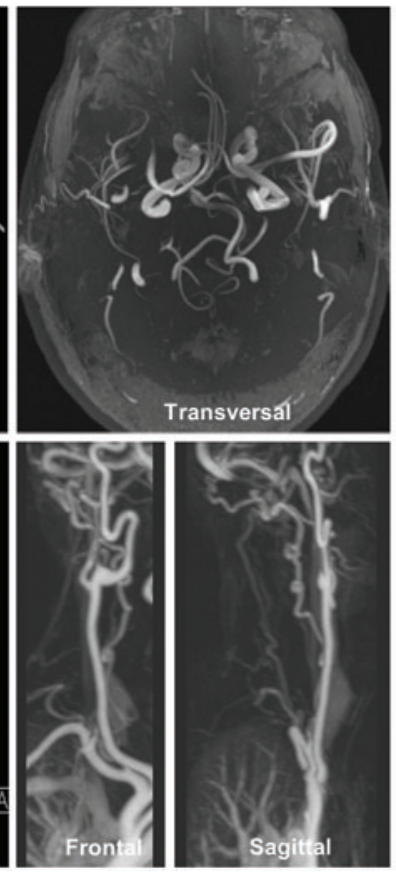

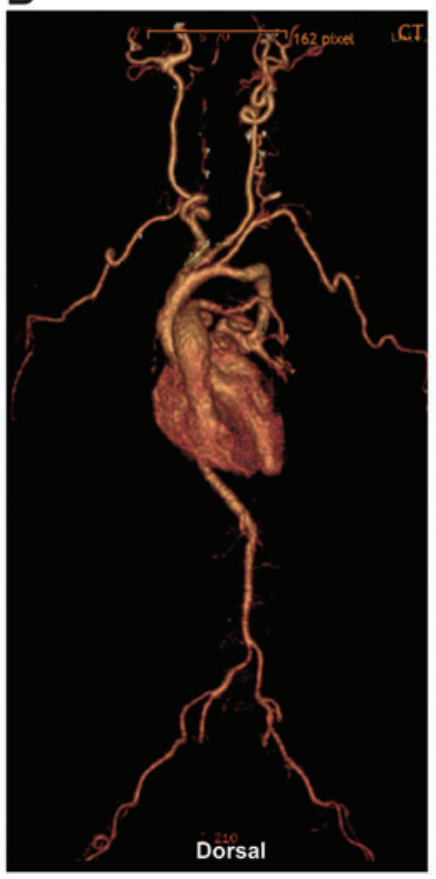

C

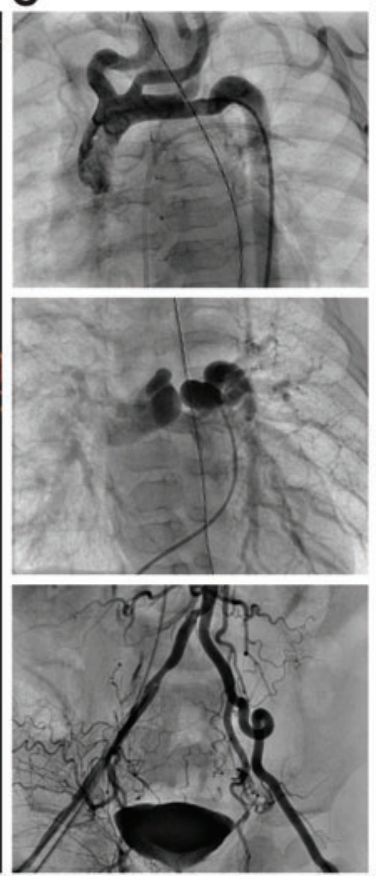

D-E
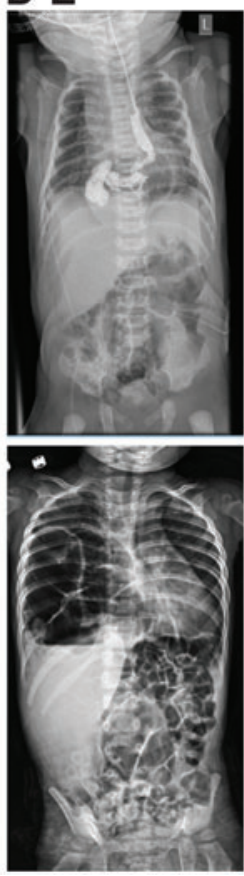

FIG. 2. Imaging studies in five patients with arterial tortuosity syndrome. (A) Magnetic resonance angiography in patient A shows moderate to severe tortuosity of the supra-aortic arteries, including the carotid, the basilar and cerebral arteries, and both iliac arteries. The aortic arch and descending aorta are gracile. There are no stenoses or aneurysms. (B) Computed tomography angiography in patient B shows a tortuous aorta with kinking, tortuosity of the middle-sized arteries, and stenosis of pulmonary arteries. The truncus pulmonalis is dilated and pulmonary arteries have a craniocaudal organization. (C) In patient C, conventional angiography reveals stenosis of the aortic isthmus, tortuosity of the aorta, pulmonary arteries, and supra-aortic, inguinal, and visceral arteries. There is mild narrowing of the pulmonary arteries. (D, E) Conventional radiography studies in patients $\mathrm{D}$ and $\mathrm{E}$ illustrate the respective presence of a hiatal and diaphragmatic hernia. Color images are available online. 


\section{Pulmonary manifestations}

In a recent cohort (9), infant respiratory distress syndrome was a relatively frequent observation that may relate to impaired lung maturation, diaphragmatic hernia, or pulmonary hypertension. Obstructive sleep apnea may be observed in older children and adults and may relate to hypotonia of the pharyngeal musculature and retrognathia. It remains to be established if patients are at risk to develop pulmonary emphysema, as has been observed in other elastinopathies (24).

\section{Ocular manifestations}

Corneal thinning and pellucid corneas are recently described manifestations in several ATS patients $(43,44)$. This may result in irregular astigmatism, keratoconus, and keratoglobus $(16,43)$. It may also associate with corneal opacities. Myopia is often present, although it is unclear if it is more frequently observed than in the general population. Laser-assisted in situ keratomileusis surgery is a risk factor for developing corneal complications (43).

\section{Connective tissue and craniofacial features}

ATS patients may have some distinctive craniofacial features that become more prominent with age (Fig. 3). Fre- quently reported features include a long face, hypertelorism, downslanting palpebral fissures, epicanthal folds, periorbital fullness, sagging cheeks, large ears, a highly arched palate, and retrognathia $(9,16)$. Bifid uvula or a cleft palate seems not to be associated with the disease, which may differentiate it from the Loeys-Dietz syndrome.

Overgrowth results in arachnodactyly and pectus deformity, while dolichostenomelia is not routinely observed. Hypermobility of small and large joints is frequently present and hypotonia may cause isolated motor delay $(9,16)$. Skin anomalies range from a thin hyperextensible skin with a velvety texture (often described as soft and doughy) to loose skin folds (cutis laxa) (Fig. 3). Wound healing is normal. Umbilical and inguinal hernias may occur (9) as well as pelvic organ prolapse in women (especially after child bearing) (20).

\section{Other manifestations}

Hiatal hernia and diaphragmatic hernia may be present in up to $30 \%$ of the patients and their presentation may vary from asymptomatic over postprandial discomfort to neonatal respiratory failure (Fig. 2) $(9,98)$. About one-third require surgical correction. Pyloric stenosis seems more prevalent $(10 \%)$ as well as urinary tract anomalies with dilatation of the pyelocaliceal system (9). Finally, some patients may have
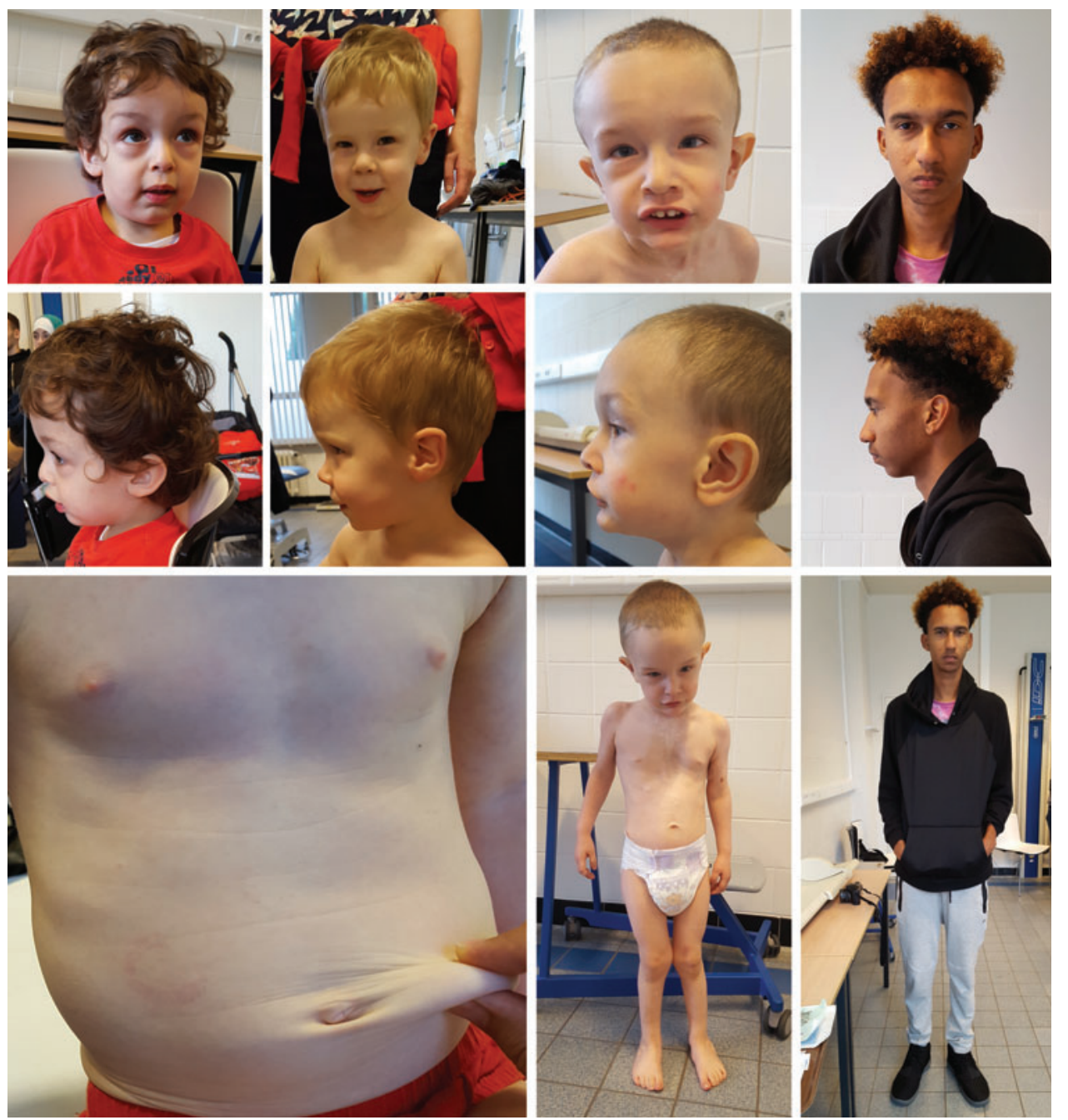

FIG. 3. Clinical characteristics in four patients with arterial tortuosity syndrome. Craniofacial features include a long face, hypertelorism, downslanting palpebral fissures, epicanthal folds, sagging cheeks, large ears, and a hooked nose. Skin involvement can range from a thin hyperextensible skin with a velvety texture to marked cutis laxa. Skeletal manifestations include joint laxity, pectus deformities, arachnodactyly, and scoliosis. Images used with permission. Color images are available online. 
lengthening of the gastrointestinal tract, resulting in esophageal tortuosity or dolichocolon. Several patients reported symptoms of autonomic dysfunction such as obstipation (that may partly be due to a dolichocolon), Raynaud phenomenon, slow eye accommodation, and orthostatic hypotension.

Many patients have psychological burdens related to both self-esteem and anxiety and distress for an uncertain vascular prognosis (Callewaert, personal observation).

A summary of the clinical characteristics and presentation rates in a series of 50 novel patients and 52 previously reported patients with a confirmed molecular diagnosis was recently presented by Beyens et al. (9).

\section{Histopathology}

Vascular tissue histology shows fragmentation of the inner elastic membrane and the elastic lamellae in the tunica media of the aortic wall. The elastic fibers are short, thickened, and disorganized, an observation made as well in other heritable disorders of the connective tissue with cardiovascular manifestations $(1,8,9,34,39,71)$. Cultured fibroblasts show disorganization of the actin cytoskeleton and multiple extracellular matrix (ECM) components, including fibronectin, fibrillin, type 3 collagen, type 5 collagen, and decorin (9, 26, 41, 102).

Transmission electron microscopy on skin biopsies of ATS patients reveals a poorly organized elastin assembly at the periphery of the elastic fiber, accompanied by infiltration of microfibrils in an interrupted elastin core (9).

\section{Patient Management}

Given the systemic manifestations associated with ATS, a coordinated and multidisciplinary approach for management and treatment is required. Treatment is largely supportive and symptomatic.

Baseline magnetic resonance arteriography from head to pelvis is required upon diagnosis and should be repeated every 3 years. During the first 5 years of life, echocardiographic follow-up every 3 months is necessary to detect aggressive aneurysm formation or evaluate pulmonary hypertension. Afterward, yearly follow-up suffices if measurements remain within normal limits (9). In case of aneurysm formation, surgical guidelines for Marfan syndrome can be applied as the risk for acute dissections on small aortic diameters seems relatively small (9). Pulmonary artery stenosis can be corrected by percutaneous surgical or hybrid approaches $(80,92)$. Systemic stenosis-if focal-may require excision and end-to-end anastomoses $(2,3,12,22,28,35,46,49,80,92)$. Currently, the experience is limited and is based on expert opinion and on personal experience of the thoracovascular surgeon (14).

In analogy with treatment strategies applied for other heritable disorders of connective tissue, such as Marfan syndrome and Loeys-Dietz syndrome, agents that reduce hemodynamic stress on the arterial wall, including beta-adrenergic blockers, angiotensin-converting enzyme inhibitors, and angiotensin II receptor 1 antagonists, such as losartan, can be considered. The experience is limited and in case of aortic hypoplasia/stenosis and/or renal stenosis, caution is necessary because of the risk of renal failure. Similarly, caution is needed to use nonsteroidal anti-inflammatory agents $(9,14)$. Pulmonary hypertension may be severe and related to pulmonary artery stenosis (causing a ventilation-perfusion mismatch), increased vascular wall ten- sion, or lung hypoplasia due to diaphragmatic hernia. Treatment depends on the cause and may require percutaneous angioplasty and/or surgery or medical treatment (e.g., with sildenafil).

Regular orthopedic (joint laxity and scoliosis), orthodontic (highly arched palate and dental crowding), pulmonary (obstructive sleep apnea syndrome, also postoperatively), and ophthalmological (keratometry and myopia) assessments are advised. Corneal cross-linking has been done in two ATS patients with corneal thinning, but long-term effectiveness needs to be established (Callewaert, personal communication). Early rehabilitation may improve motor function in case of joint hyperlaxity and hypotonia. Above all, patients should remain active in moderation (aerobic joint-gentle activities, such as swimming), as advised for other connective tissue disorders.

\section{Differential diagnosis}

ATS clinically shows some overlapping vasculopathy with other heritable disorders of the connective tissue. More specifically, autosomal recessive cutis laxa type 1B (ARCL type 1B) (76) caused by mutations in fibulin-4, encoding for the elastinbinding protein fibulin-4, is also associated with arterial tortuosity, arterial aneurysms, and stenosis, although ARCL type 1B more commonly leads to focal stenosis at the aortic isthmus and a more aggressive arterial phenotype. Furthermore, Loeys-Dietz syndrome, caused by heterozygous pathogenic variants in genes involved in transforming growth factor beta (TGF $\beta$ ) pathway signaling, such as TGF $\beta$ cytokines (TGFB2 and TGFB3), TGF $\beta$ receptors (TGFBR1 and TGFBR2) and signal transducers (SMAD2 and SMAD3), is characterized by cerebral, thoracic, and abdominal arterial aneurysms and/or dissections (55).

Occipital horn syndrome, an X-linked disorder caused by mutations in ATPase copper-transporting alpha (ATP7A), presents not only with intracranial vascular tortuosity but also with distinctive skeletal and urogenital features (10). Loose skin may be reminiscent of different types of cutis laxa, including ARCL type 1A, type 1B, type 1C, and ARCL type 2. When the skin is rather hyperextensible, it should be differentiated from the Ehlers-Danlos syndrome, hypermobility and vascular type (14).

\section{Phenotypic Analysis of Animal Models for ATS}

To date, two mouse models have been described for ATS. These models were generated through $N$-ethyl- $N$-nitrosourea mutagenesis in mice with a $\mathrm{C} 3 \mathrm{HeB} / \mathrm{FeJ}$ background. Two lines harboring missense mutations in Slc2alo (c.383G $>\mathrm{A}-$ p.G128E and c.449C>T - p.S150F) were recovered, and these nucleotide alterations were predicted to be deleterious (15).

Callewaert et al. executed comparative studies on wildtype, heterozygous, and homozygous mice at 5 months of age, including ultrasound analysis of the abdominal aorta, whole-animal vascular corrosion casting, and histological analysis of the tail and popliteal arteries. For both lines, none of the examinations revealed ATS-related phenotypic abnormalities. Suggested explanations for an absent phenotype include (i) several GLUT family members may show functional redundancy, thus compensating for the loss of GLUT10; (ii) phenotypic penetrance is hindered by the used genetic background (C3HeB/FeJ); and (iii) GLUT10 does not contribute to vasculogenesis in mice (15).

Utilizing the same mouse models, Cheng et al. executed a series of additional experiments (21). Again, echocardiograms 
did not reveal any abnormalities, and using brain magnetic resonance angiography, architectural anomalies in the cerebral arteries such as tortuosity, stenosis, or aneurysms could not be detected at 10 months of age. Histopathological analysis, however, disclosed a mild vascular phenotype, which was more severe in mutant mice carrying the p.G128E mutation (in comparison with the p.S150F mutant) and in older mice (10 months of age vs. 6 months of age). Older mutant mice had a higher blood pressure and displayed a thickened and irregularly shaped vessel wall, fragmented elastic fibers with a disruption of the internal elastic lamina, and hypertrophy of endothelial cells in the tunica intima (21).

In 2012, Willaert et al. published a report on an slc2a10 zebrafish knockdown model (95). Morpholino-injected embryos (morphants) showed several cardiovascular abnormalities: cardiac edema, a reduced heart rate and blood flow, and an incomplete and irregular patterning of the vasculature, resulting in disrupted blood flow in the sinus venosus. These anomalies possibly represent developmental precursors to vascular anomalies, as observed in ATS patients.

\section{Molecular Background}

ATS exhibits autosomal recessive inheritance and approximately a decade ago, its causal gene, SLC2A10, was identified (26). The protein it encodes (GLUT10) is a member of the facilitative GLUTs, which are involved in assisting the transport of monosaccharides, polyols, and other small carbon compounds across eukaryotic cell membranes (63). The GLUT family consists of 14 proteins, which are categorized into three classes based on sequence similarity: class 1 (GLUTs 1-4 and 14), class 2 (GLUTs 5, 7, 9, and 11) and class 3 (GLUTs 6, 8, 10, 12, and H+/myo-inositol cotransporter). The general structure of each GLUT protein is similar: 12 transmembrane domains connected by linker domains, cytoplasm-pointing amino and carboxy termini, and a unique $\mathrm{N}$-linked oligosaccharide side chain, positioned in the first (classes 1 and 2) or fifth (class 3) exofacial linker domain (63).
In GLUT10, this particular extracellular loop is distinctively larger in size compared with the other GLUT family members. Some authors have speculated that this loop may attribute alternative functions to GLUT10 (60). However, none of the 34 known mutations causing ATS reside in this exofacial linker domain (9), possibly reflecting a less critical role of this domain.

\section{Hypotheses for the Pathophysiology of ATS}

GLUT10 is widely expressed, but is most abundant in smooth muscle-rich organs (97), which correlates with its importance in blood vessel development and homeostasis. Other organs showing expression are the heart, placenta, lung, liver, skeletal muscle, pancreas, brain, kidney (32, 60), and adipose tissue (96).

On a subcellular level, GLUT10 has been localized to the nuclear envelope (NE) (26), ER (82), mitochondria, and Golgi apparatus (53). The diverse expression patterns indicate that GLUT10 may translocate in different cellular states. Initially, human GLUT10-expressed in Xenopus laevis oocytes - was shown to facilitate transport of D-glucose, Dgalactose, and 2-deoxy-D-glucose (32) with high affinity. Subsequent studies favored DHA as a substrate. Based on the subcellular localization of GLUT10 and the range of functions its presumable substrates can fulfill, a number of disease hypotheses for ATS have been postulated and investigated.

\section{Inhibition of glucose-mediated transcriptional regulation in the nucleus}

Coucke et al. localized GLUT10 in the perinuclear region and identified TGF $\beta$ pathway upregulation in ATS patients (26). According to the hypothesis, deficiency of GLUT10 would result in reduced nuclear glucose levels, downregulating transcription of genes with glucose-responsive elements in their promoter regions. One such gene is $D C N$ encoding the proteoglycan, decorin. Decorin sequesters TGF $\beta$ (37) and its expression was reduced in cultured vascular smooth muscle cells (SMCs) of ATS patients. Consequently, TGF $\beta$-driven expression of the proteoglycan, versican, was increased (26). Versican has an inhibitory role on elastic fiber assembly (94)
Plasma membrane

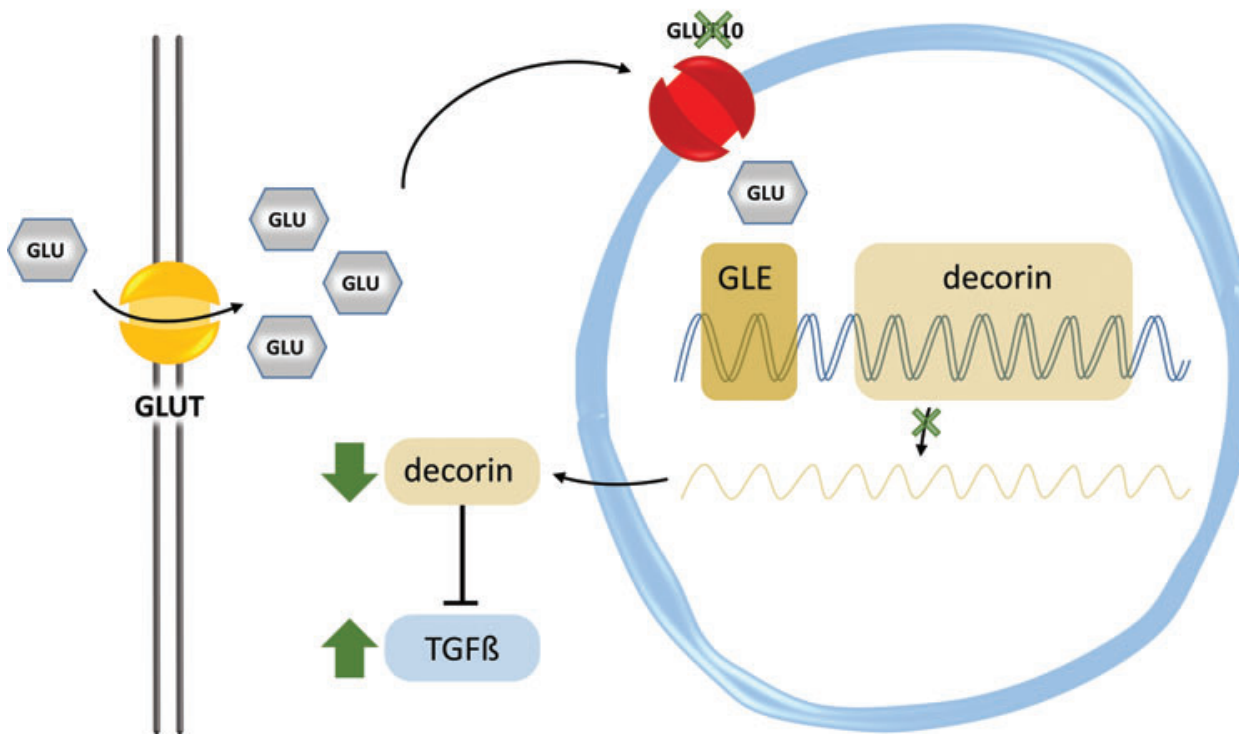

FIG. 4. Schematic representation of the hypothesis proposed by Coucke et al. (26), in which GLUT10 serves as a nuclear transporter of glucose. Intranuclear glucose can trigger transcription of genes harboring glucose-responsive elements (GLEs) in their promoter regions, such as decorin, which is known to inhibit TGF $\beta$ pathway activation by sequestering TGF $\beta$. A GLUT10 defect (indicated by a green $\mathrm{X}$ ) would lead to downregulation of decorin and triggering of the TGF $\beta$ pathway (green arrows). GLU, glucose, Na, sodium; $\mathrm{TGF} \beta$, transforming growth factor beta. Color images are available online. 
and its increased expression could explain failed elastogenesis in ATS (Fig. 4).

Nevertheless, the role of GLUT10 as a nuclear GLUT is questionable based on the following: (i) small polar molecules such as glucose are able to enter the nucleus via diffusion through the nuclear pore, hence not requiring specialized transporters, and (ii) glucose-dependent transcription is not directly mediated by intranuclear glucose, but rather by indirect mechanisms transducing the glucose signal to the genome (82).

\section{Oxidative stress}

Several studies, described in detail below, pointed toward a contribution of oxidative stress in the pathogenesis of ATS. Disturbed redox status and increased reactive oxygen species (ROS) production, promoting protein oxidative modifications, can modulate signaling molecule activities and dysregulate key pathological cellular processes, such as apoptosis, migration, proliferation, inflammation, and ECM component degradation, accumulating in vascular remodeling as observed in ATS (38).

A first study, performed by Lee et al., confirms that GLUT10 operates as a DHA transporter (53). They observed that exogenous tagged GLUT10 localized primarily to the mitochondria in rat A10 SMCs and insulin-stimulated mouse 3T3-L1 adipocytes, while the protein localized to the Golgi apparatus in mouse NIH3T3 fibroblast cells. Mitochondrial import of DHA increased in a dose-dependent manner and following oxidative stress upon $\mathrm{H}_{2} \mathrm{O}_{2}$ administration.

These findings prompted a second hypothesis (Fig. 5) where GLUT10 has a major role in replenishing mitochondrial antioxidative capacities through DHA transport. Under normal conditions, both DHA and AA are transported into the cytoplasm, where most DHA is reduced to AA. Under oxidative conditions, DHA accumulates in the cytoplasm and is transported to the mitochondria in a GLUT10-dependent manner, followed by its regeneration to AA. There, AA exerts its function as an antioxidant, quenching ROS molecules and free radicals, protecting the cell from damage due to oxidative stress. A GLUT10 defect would result in accumulation of ROS molecules, which might trigger development of ATS-related anomalies (53).

A couple of arguments, however, dispute this pathogenesis model. A recent in silico study identified GLUT10 as one of the transporters with the lowest predicted mitochondrial localization score (87). In addition, the sodium-coupled ascorbic acid transporter-2 (SVCT2) has already been identified as a mitochondrial AA transporter, questioning the necessity of GLUT10 for mitochondrial DHA transport $(5,64)$.

This hypothesis was nonetheless reinforced by the same laboratory with additional data obtained on rat, mouse, and human SMCs. This study revealed that stress and aging conditions increased intracellular and mitochondrial ROS levels and promoted targeting of GLUT10 to the mitochondria, increasing mitochondrial DHA uptake. In addition, GLUT10 knockdown and overexpression models in mouse MOVAS SMCs, respectively decreased or increased the inner mitochondrial membrane potential and oxygen consumption rate (86). Compared with control SMC, SMCs from GLUT10 ${ }^{\mathrm{G} 128 \mathrm{E}}$ mice showed higher ROS levels, both intracellularly and in the mitochondria, a reduced oxygen consumption rate, and altered mitochondrial morphology and density. These features were also confirmed in aortic tissue of 15-month-old GLUT10 ${ }^{\mathrm{G} 128 \mathrm{E}}$ mice. (86).

Comparative transcriptome analysis at $48 \mathrm{~h}$ postfertilization between slc2al0 morphants (following morpholino-based slc2a10 knockdown) and control embryos revealed altered
FIG. 5. Graphical representation of the mitochondrial dysfunction ATS pathogenesis hypothesis (53). Both DHA and AA are transported into the cytosol by GLUT or SVCT, respectively. In the cytosol, reductase converts most DHA to AA. Under oxidative conditions (indicated by red icons), however, cytosolic DHA accumulation is followed by its transportation into the mitochondria in a GLUT10-dependent manner. There, regenerated AA acts as an antioxidant. A GLUT10 defect (indicated by a green $\mathrm{X}$ ) leads to accumulation of ROS molecules (green arrows). Na, sodium; ROS, reactive oxygen species; SVCT, sodium-dependent vitamin C transporter. Color images are available online.

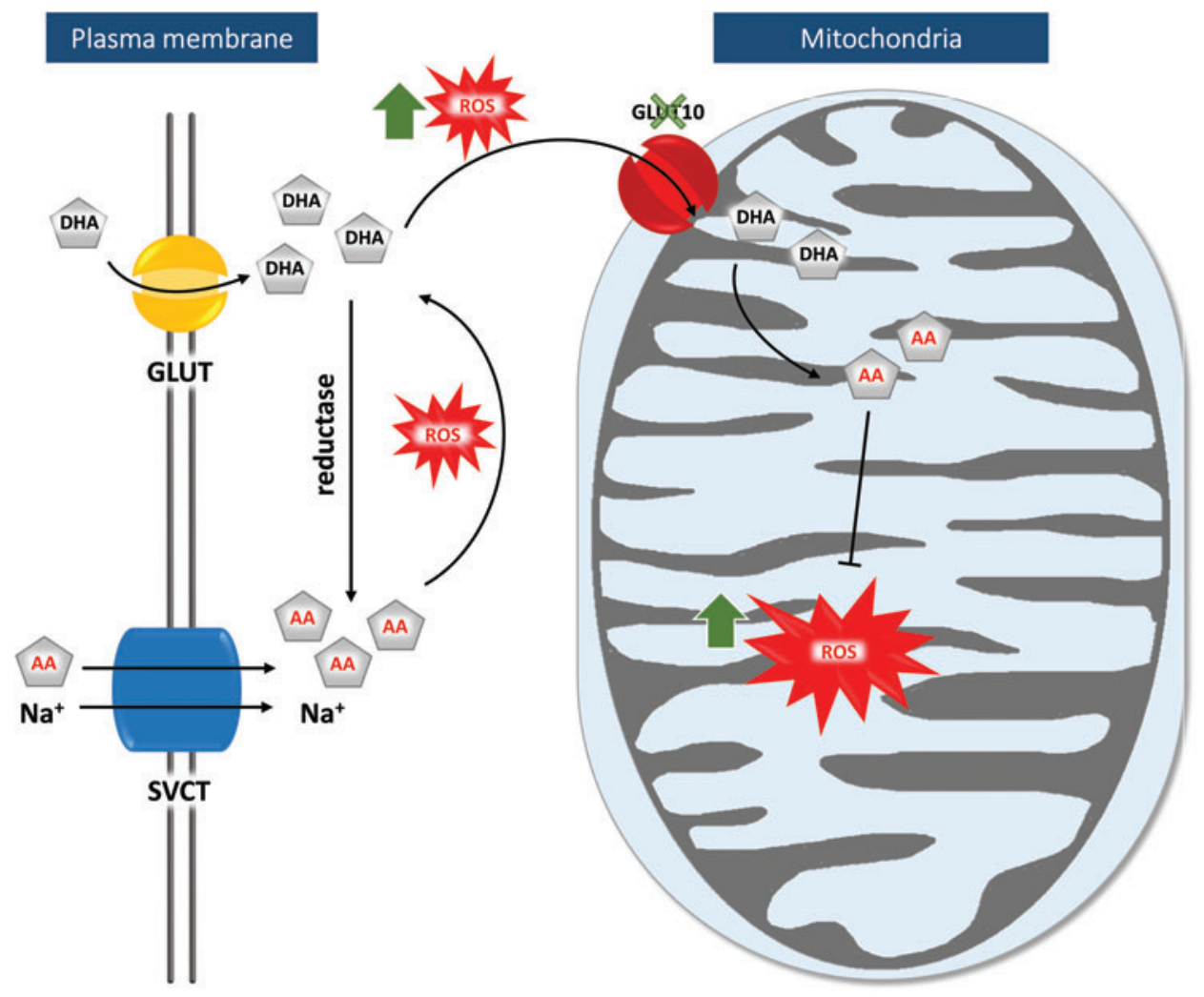


expression of genes involved in oxidative phosphorylation, reactive oxygen production, the Szent-Györgyi-Krebs cycle, the glycolysis/gluconeogenesis pathway, and glycogen metabolism. These findings suggested mitochondrial dysfunction as a pathomechanism, which was further validated by impaired oxygen consumption rates in morphants. In contrast to observations made in the ATS mouse model, electron microscopy analysis of slc2a10 morphants did not reveal any changes in mitochondrial morphology (95).

\section{Disturbed post-translational modification in the ER}

In silico tools predict GLUT10 localization in the ER with high probability (40) because of the presence of an ER retention signal YXXI/V (48) and a Lys-Arg-Arg (KRR) motif (42) in the $\mathrm{C}$-terminus of the protein. Since ATS patients show a remarkable clinical overlap with heritable disorders of the connective tissue with abnormal collagen and/or elastin homeostasis, Segade hypothesized that GLUT10 operates as a transporter of AA, a necessary component for post-translational modification of collagen and elastin molecules in the ER (82).

AA - being a cofactor of prolyl and lysyl hydroxylasescatalyzes the hydroxylation of proline and lysine residues in elastin and collagen, thereby facilitating cross-link formation. Lowered AA levels in the ER would result in defective and immature collagen and elastin molecules, contributing to histopathology observed in collagen- and elastin-rich tissues in ATS patients (Fig. 6). In this scenario, the observed

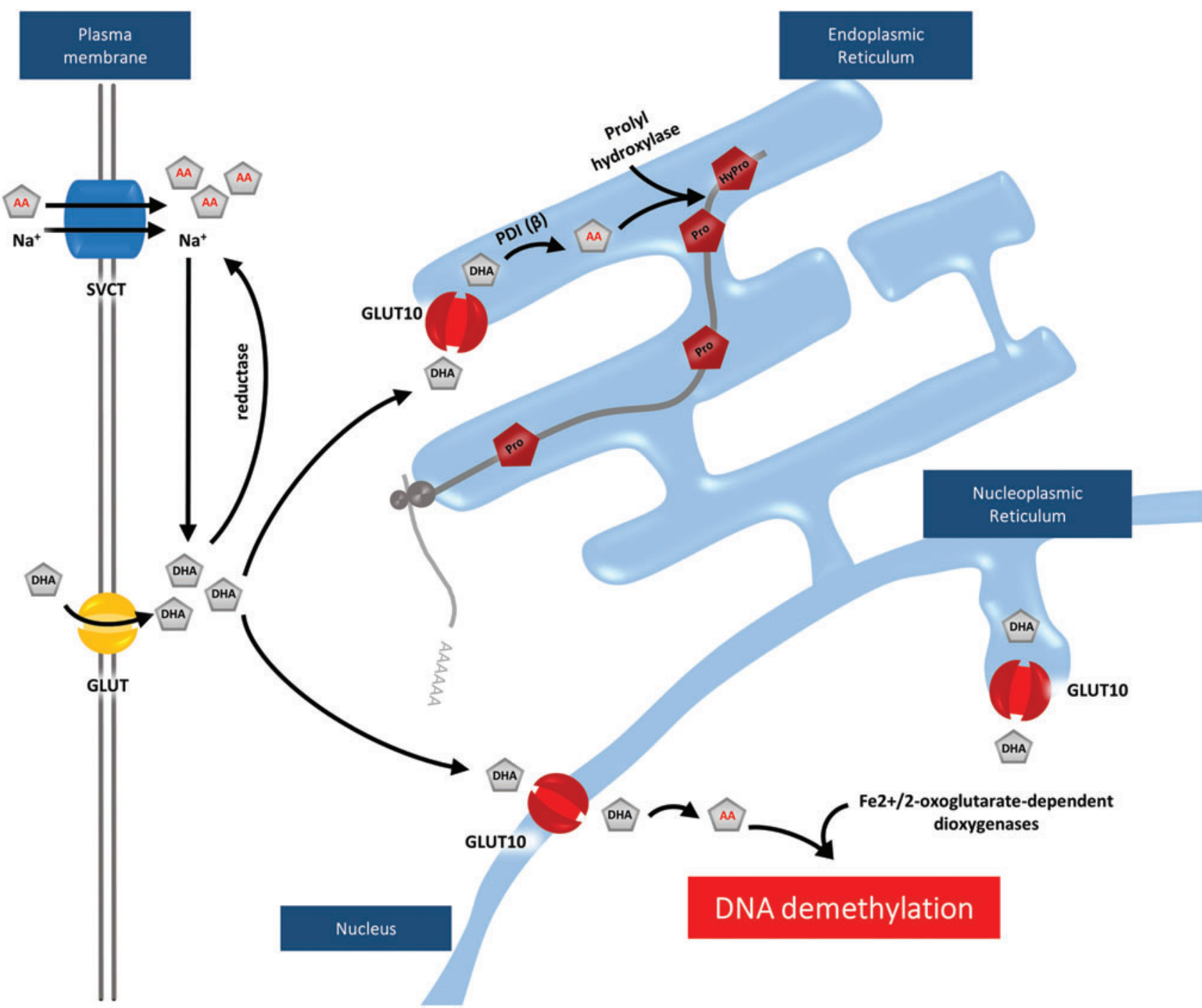

FIG. 6. Schematic representation of the hypothetical model proposed by Segade (82) and Németh et al. (67), where GLUT10 functions as a DHA transporter in the ER-NE continuum. Segade proposes that GLUT10 facilitates DHA transport to the ER, after which conversion to AA by PDI takes place. In the ER, AA functions as a cofactor of prolyl and lysyl hydroxylases, which modify proline and lysine residues in collagen and elastin molecules, leading to their stabilization. A GLUT10 defect would lead to deposition of immature collagen and elastin molecules, weakening of the extracellular matrix, and subsequent triggering of the TGF $\beta$ pathway. Németh et al. suggest that GLUT10 transports DHA into the nucleoplasm, either directly through the membranes of the nuclear envelope or via the ER, through the ER-NE continuum, where regenerated AA functions as a cofactor for DNA and histone demethylases. ER, endoplasmic reticulum; Fe, iron; HyPro, hydroxyproline; Na, sodium; NE, nuclear envelope; PDI, protein disulfide isomerase; Pro, proline. Color images are available online. 
upregulation of the TGF $\beta$ pathway in ATS patients would result from weakening of the ECM and increased activation of latent TGF $\beta$ molecules (82).

This hypothesis has been experimentally supported by identification of GLUT10 as a DHA transporter in the ER. Transient transfection of GLUT10-green fluorescent protein constructs in rat SMCs confirmed the presence of GLUT10 in the ER (82). Furthermore, immunocytochemistry-supported localization experiments, either employing ATS patient cells or exogenous tagged GLUT10, showed a reticular distribution and perinuclear abundance of the protein in fibroblast cells $(40,102)$, and GLUT10 was found to be present in microsomal (ER-derived) fractions obtained from human fibroblasts and liver tissue (40).

Incorporation of in vitro-produced GLUT10 into liposomes resulted in efficient transport of DHA in a concentrationdependent manner. Moreover, selective permeabilization experiments in fibroblasts showed that the transport of DHA through endomembranes was markedly reduced in ATS patient cells when compared with control fibroblasts (66).

\section{Epigenetic modulation through $A A$ deficiency in the nucleoplasm}

Recently, nucleoplasmic JmjC domain-containing demethylases $(50,90)$ and ten-eleven translocation methylcytosine dioxygenases $(47,51)$, all members of the AA-dependent $\mathrm{Fe}^{2+} / 2$-oxoglutarate-dependent dioxygenases, gained attention since they promote demethylation of histones and DNA, respectively. Both mechanisms are involved in epigenetic regulation of transcription (17).

It has recently been shown that by applying highresolution immunoelectron microscopy and immunogold labeling of AA (99), AA accumulation in the nucleoplasm was diminished in ATS fibroblasts (67). Since the syndrome is due to mutations in GLUT10, it can be supposed that GLUT10 is required for the proper AA concentration in the nucleus.

Because the membranes of the ER and the NE are continuous, DHA uptake by GLUT10 in the nucleoplasm can theoretically follow two routes. DHA can be transferred from the ER across the inner membrane of the NE to the nucleoplasm. Alternatively, DHA could be transported directly through the membranes of the NE (Fig. 6). As a consequence, altered DNA hydroxymethylation patterns at both the global level and at specific gene regions (including $P P A R G$ encoding peroxisome proliferator-activated receptor [PPAR] $\gamma$ ) were found in ATS patient fibroblasts (67), which suggests an epigenetic role of AA transport in the ATS pathomechanism.

\section{Discussion}

Vitamin C compartmentalization: unifying the different disease mechanisms?

Scurvy, a generalized AA deficiency due to insufficient AA intake, has been known long before the discovery of AA and causes muscular weakness, pain, generalized bleeding, and impaired wound healing. Scurvy at the cellular level can manifest with normal intake and serum concentrations of AA. This latent or tissue scurvy may contribute to complications of insulin-dependent diabetes mellitus, such as endothelial dys- function and atherosclerosis (73), due to competition between glucose and DHA for GLUTs during hyperglycemia $(29,72)$.

In a series of elegant experiments, it has been demonstrated that subcellular scurvy may also result from either increased consumption of AA in a cellular compartment or defective transport into a specific organelle. Zito et al. studied the effect of the combined loss-of-function mutations in genes encoding the ER thiol oxidases ERO1 $\alpha, \mathrm{ERO} 1 \beta$, and peroxiredoxin 4 in a murine model. These enzymes catalyze electron transfers implicated in oxidative protein folding (101). Surprisingly, only minor alterations in disulfide bond formation were found, suggesting the presence of alternative electron transfer routes. However, low tissue AA concentrations and decreased 4-hydroxyproline content of procollagen were observed.

Hence, in the absence of ER thiol oxidases, cysteinyl thiol groups are oxidized to sulfenic acid through an alternative hydrogen peroxide-dependent way, consuming AA as a reductant (100). This competes with prolyl hydroxylases for AA in the ER lumen, resulting in impaired procollagen hydroxylation, and impairs ECM homeostasis, causing scurvylike disease. Thus, neither AA synthesis (mice are able to produce AA) nor AA transport could keep pace with the increased consumption.

Due to the presence of transporters, competition may arise between AA-requiring reactions of two (or more) compartments as well. For instance, in pluripotent stem cells, increased prolyl-4-hydroxylase activity in the ER hampers 5 -methylcytosine demethylation in the nucleoplasm, affecting epigenetic regulation, and vice versa (30). Genetic ablation of prolyl-4-hydroxylase subunit alpha-2 or its pharmacological inhibition reverted epigenetic changes and antagonized cell state transition. Thus, it can be hypothesized that AA consumption in the ER by collagen hydroxylation reduces AA availability for DNA and histone demethylases in the nucleoplasm, preventing mesenchymal transition.

Finally, mislocalization or translocation of AA/DHA transporters can also influence vitamin $\mathrm{C}$ distribution between two neighboring compartments. Indeed, Pena et al. demonstrated that normal and cancer cells handle AA differently (69). Human breast cancer tissues expressed SVCT2, but were not able to take up AA. This was explained by the fact that this form of SVCT2 was absent from the plasma membrane and expressed in mitochondria of breast cancer cells (78). Augmented expression of the SVCT2 mitochondrial form and mitochondrial sequestration of AA might profoundly alter AA-dependent mechanisms in other subcellular compartments and might represent an adaptation mechanism to the special metabolic features in cancer cells.

These mechanisms balancing transport and consumption within and between cellular compartments may participate in the pathogenesis of ATS, although still several aspects remain to be addressed.

\section{Pathophysiological mechanisms related to oxidative stress}

Different lines of evidence support a role for GLUT10 in DHA transport through the ER-NE continuum or the contribution of oxidative stress to the ATS pathomechanisms. The complementarity and hierarchy of these identified disease mechanisms need further investigation, as well as the exact 
role of GLUT10 herein. However, molecular alterations linked to ATS pathogenesis were rescued upon reexpression of GLUT10 in ATS patient fibroblasts (under low, nonphysiological AA concentrations), suggesting that GLUT10 might also harbor transport-independent functions $(102,103)$.

Comparable with the zebrafish morpholino model, transcriptome analysis comparing ATS patient and control cells identified affected redox homeostasis, energy and lipid metabolism, TGF $\beta$ signaling, and ECM architecture (102). Of note, the most upregulated gene was $A L D H 1 A 1$, encoding a member of the aldehyde dehydrogenases (ALDHs). ALDHs act in detoxification induced by sustained presence of lipid peroxidation (LPO)-derived molecules that were found to be increased in ATS fibroblasts. Elevated ROS levels in ATS fibroblasts were suggested to initiate the LPO mechanism by interaction with polyunsaturated fatty acids (PUFAs).

Furthermore, PPAR $\gamma$ activity is boosted by peroxidized PUFAs and an altered cellular energy metabolism. PPAR $\gamma$ is a master regulator in multiple (patho)physiological processes and influences transcription and post-translational modification events. Oxidative stress in ATS might depend on a PPAR $\gamma$-dependent mechanism through a maladaptive feedback, upregulating $\beta$-oxidation, and PUFA metabolism, establishing a vicious circle of oxidative stress induction. ROS directly promote ECM protein fragmentation and induce LPO-derived molecules that could hamper the secretion and organization of collagen and elastin molecules in the ECM, causing ER stress (102).

TGF $\beta$ signaling: a delicate balance at the crossroads of oxidative stress, defective ECM production, and epigenetic modification

A key pathway in multiple heritable disorders of connective tissue with cardiovascular implications is TGF $\beta$ signaling. Initial immunostaining experiments for connective tissue growth factor and pSMAD2 on arterial tissue of one ATS patient demonstrated an extreme increase in signal intensity in comparison with control tissue (26). Similar analyses in skin and artery tissue in a subsequent study could not confirm this observation (9). These observations likely point to variability in spatiotemporal TGF $\beta$ signaling and add to the uncertainty regarding the (primary) role of TGF $\beta$ signaling in the disease mechanisms underlying elastic fiber diseases.

$\operatorname{TGF} \beta$ is secreted in the ECM in its latent form, called the large latent complex (LLC), comprising TGF $\beta$, latencyassociated peptide (LAP), and latent TGF $\beta$-binding proteins, which are covalently cross-linked to ECM components. TGF $\beta$ can be released from this complex through LAP proteolysis, interaction with $\alpha \mathrm{v}$-containing integrins such as $\alpha \mathrm{v} \beta 3$ integrin, or ROS-induced mechanisms.

Disturbed TGF $\beta$ signaling has been claimed to be a primary actor in ATS pathogenesis (26), or to result secondarily from increased release of latent TGF $\beta$ from a damaged ECM (82), due to ineffective hydroxylation of collagen and elastin. Furthermore, epigenetic inhibition of $\operatorname{PPAR} \gamma$ will enhance TGF $\beta$ signaling, and ROS contribute to the release of active TGF $\beta$ from the LLC.

Finally, Zoppi et al. found a key role for $\alpha \mathrm{v} \beta 3$ integrin, cross talking with noncanonical TGF $\beta$ signaling. More specifically, $\alpha \mathrm{v} \beta 3$ integrin-dependent release of TGF $\beta$ from the LLC induces $\alpha \mathrm{v} \beta 3$ integrin association with TGF $\beta$ receptor II and noncanonical TGF $\beta$ pathway stimulation through $\mathrm{p} 38$ MAPK (102). This is supported by an increased presence of $\mathrm{TGF} \beta$ receptor II, $\alpha \mathrm{v} \beta 3$, integrin, and $\mathrm{p} 38 \mathrm{MAPK}$, but lowered pSMAD2, a biomarker for canonical TGF $\beta$ signaling, in mock-transfected ATS patient fibroblasts compared with GLUT10 transfected ATS cells. Although p38 MAPK is a negative regulator of cellular stress, it does not seem to correct ECM organization, as demonstrated by staining of several ECM components in ATS patient fibroblasts.

\section{Future Perspectives}

The different hypotheses provide paradigms to understand ATS pathophysiology and developmental biology of the arteries, but none of them are currently supported by sufficient evidence to be regarded as the sole, or even main, mechanism. Nevertheless, the formulated hypotheses are not mutually exclusive.

Indeed, GLUT10 may translocate to different organelles depending on the cell state $(25,40,53,82,102)$. Moreover, intracellular membranes as well as the plasma membrane are no longer regarded as static structures, but instead are attributed to plasticity, interchanging phospholipids, and membrane-bound (or enclosed) molecules through physical links and/or transport mechanisms. Of note, a complex, ERmitochondria encounter structure, brings ER and mitochondrial membranes in close proximity and is necessary for cell survival (52). In a related disorder, occipital horn syndrome caused by deficiency of the copper ATPase, encoded by $A T P 7 A$, it has been shown that the molecule translocates from the cell membrane to trans- and post-Golgi compartments depending on copper concentration (70).

Finally, as discussed above, it is crucial to understand the balance between AA use, import, and transport between organelles both under physiological and GLUT10-deficient states. Accumulating evidence shows that local subcellular concentrations of vitamin $\mathrm{C}$ are equally or even more important than the global cellular or blood levels. Mapping of subcellular AA concentrations, determination of the redox state of the AA/DHA couple in the different cellular compartments, and exploration of AA/DHA transport mechanisms between the cytoplasm and various organelles, both under physiological and diverse pathological situations, are future challenges.

This knowledge will lead to a more detailed understanding of known and yet unknown functions of AA in the different cellular compartments in health and disease. Knowing the importance of AA in vascular development and homeostasis (as evidenced by, respectively, ATS and scurvy), this knowledge will contribute to understanding neovascularization both in desirable (wound healing, neovascularization after vascular injury, or thrombosis) or undesirable (tumor formation) states.

Furthermore, we should keep in mind that in vivo versus in vitro experiments may reveal completely different biological outcomes, as has been observed for the Loeys-Dietz syndrome, caused by mutations in TGFBR2 $(31,61)$. In addition, observed pathophysiological aberrations in postdevelopmental life may be protective in early development (when the arterial system is being developed) (23). Similarly, the damaged arterial wall may behave differently on blood pressure when still developing or in postnatal life (as hypothesized for intracranial tortuosity in autosomal dominant cutis laxa due to ALDH18A1 defects) $(36,85)$. Finally, it may prove difficult 
to distinguish primary versus secondary effects. Indeed, while increased TGF $\beta$ signaling seems a common final pathway in many vascular disorders, it remains to be resolved whether it precedes ECM remodeling or whether it is a secondary effect of altered ECM homeostasis.

Animal models could be extremely helpful to test the different hypotheses. Unfortunately, the reported mouse models with missense mutations showed extremely mild phenotypes, not reminiscent of the severe cardiovascular anomalies encountered in ATS patients. Therefore, it is questionable if the mild phenotypic differences observed in older GLUT10 ${ }^{\mathrm{G} 128 \mathrm{E}}$ mice are relevant to study ATS pathogenesis. Genetic compensation might be at play to counteract the mechanisms induced upon Slc2a10 mutations. Moreover, since mice are able to synthesize AA, it can be anticipated that the abovementioned results should be interpreted with caution. It is possible that mice will present with a more relevant ATS-related phenotype if made incapable of synthesizing AA (82). Alternatively, CRISPR/ Cas9 knockout and knockin approaches in zebrafish might be a good alternative, especially since results on the morphants were motivating (95).

\section{Acknowledgments}

B.C. is a senior clinical investigator of the Research Foundation-Flanders (FWO). É.M. was supported by the János Bolyai Research Scholarship from the Hungarian Academy of Sciences and by the New National Excellence Program from the Ministry of Human Capacities.

\section{Author Disclosure Statement}

No competing financial interests exist.

\section{Funding Information}

This research is supported by FWO funds VS.080.16N, FWOOPR2013025301, and by the Hungarian National Research, Development and Innovation Office (NKFIH grant number: FK124442).

\section{References}

1. Ades LC, Knight WB, Byard RW, Bateman JF, Esquivel JA, Mee RB, Haan EA, and Milewicz DM. Clinicopathologic findings in congenital aneurysms of the great vessels. Am J Med Genet 66: 289-299, 1996.

2. Al-Khaldi A, Alharbi A, Tamimi O, and Mohammed Y. Successful surgical pulmonary artery reconstruction in arterial tortuosity syndrome. Ann Thorac Surg 88: 13431345, 2009.

3. Al-Khaldi A, Mohammed Y, Tamimi O, and Alharbi A. Early outcomes of total pulmonary arterial reconstruction in patients with arterial tortuosity syndrome. Ann Thorac Surg 92: 698-704; discussion 704, 2011.

4. Albuisson J, Moceri P, Flori E, Belli E, Gronier C, and Jeunemaitre X. Clinical utility gene card for: arterial tortuosity syndrome. Eur J Hum Genet 23:1432, 2015.

5. Azzolini C, Fiorani M, Cerioni L, Guidarelli A, and Cantoni O. Sodium-dependent transport of ascorbic acid in U937 cell mitochondria. IUBMB Life 65: 149-153, 2013.

6. Banhegyi G, Benedetti A, Margittai E, Marcolongo P, Fulceri R, Nemeth CE, and Szarka A. Subcellular com- partmentation of ascorbate and its variation in disease states. Biochim Biophys Acta 1843: 1909-1916, 2014.

7. Banhegyi G, Braun L, Csala M, Puskas F, and Mandl J. Ascorbate metabolism and its regulation in animals. Free Radic Biol Med 23: 793-803, 1997.

8. Beuren AJ, Hort W, Kalbfleisch H, Muller H, and Stoermer J. Dysplasia of the systemic and pulmonary arterial system with tortuosity and lengthening of the arteries. A new entity, diagnosed during life, and leading to coronary death in early childhood. Circulation 39: 109-115, 1969.

9. Beyens A, Albuisson J, Boel A, Al-Essa M, Al-Manea W, Bonnet D, Bostan O, Boute O, Busa T, Canham N, Cil E, Coucke PJ, Cousin MA, Dasouki M, De Backer J, De Paepe A, De Schepper S, De Silva D, Devriendt K, De Wandele I, Deyle DR, Dietz H, Dupuis-Girod S, Fontenot E, Fischer-Zirnsak B, Gezdirici A, Ghoumid J, Giuliano F, Diez NB, Haider MZ, Hardin JS, Jeunemaitre X, Klee EW, Kornak U, Landecho MF, Legrand A, Loeys B, Lyonnet S, Michael H, Moceri P, Mohammed S, MuinoMosquera L, Nampoothiri S, Pichler K, Prescott K, Rajeb A, Ramos-Arroyo M, Rossi M, Salih M, Seidahmed MZ, Schaefer E, Steichen-Gersdorf E, Temel S, Uysal F, Vanhomwegen M, Van Laer L, Van Maldergem L, Warner D, Willaert A, Collins TR, Taylor A, Davis EC, Zarate Y, and Callewaert B. Arterial tortuosity syndrome: 40 new families and literature review. Genet Med 10:1236-1245, 2018.

10. Beyens A, Van Meensel K, Pottie L, De Rycke R, De Bruyne M, Baeke F, Hoebeke P, Plasschaert F, Loeys B, De Schepper S, Symoens S, and Callewaert B. Defining the clinical, molecular and ultrastructural characteristics in occipital horn syndrome: two new cases and review of the literature. Genes 10: pii: E528, 2019.

11. Blaszczak W, Barczak W, Masternak J, Kopczynski P, Zhitkovich A, and Rubis B. Vitamin C as a modulator of the response to cancer therapy. Molecules (Basel, Switzerland) 24: pii: E453, 2019.

12. Bottio T, Bisleri G, Piccoli P, and Muneretto C. Valvesparing aortic root replacement in a patient with a rare connective tissue disorder: arterial tortuosity syndrome. $J$ Thorac Cardiovasc Surg 133: 252-253, 2007.

13. Burzle M, Suzuki Y, Ackermann D, Miyazaki H, Maeda N, Clemencon B, Burrier R, and Hediger MA. The sodiumdependent ascorbic acid transporter family SLC23. Mol Aspects Med 34: 436-454, 2013.

14. Callewaert B, De Paepe A, and Coucke P. Arterial Tortuosity Syndrome. In: GeneReviews $((R))$, edited by Adam MP, Ardinger HH, Pagon RA, Wallace SE, Bean LJH, Stephens K, Amemiya A. Seattle, WA: University of Washington, 1993.

15. Callewaert BL, Loeys BL, Casteleyn C, Willaert A, Dewint P, De Backer J, Sedlmeier R, Simoens P, De Paepe $\mathrm{AM}$, and Coucke PJ. Absence of arterial phenotype in mice with homozygous slc2A10 missense substitutions. Genesis (New York, N.Y.: 2000) 46: 385-389, 2008.

16. Callewaert BL, Willaert A, Kerstjens-Frederikse WS, De Backer J, Devriendt K, Albrecht B, Ramos-Arroyo MA, Doco-Fenzy M, Hennekam RC, Pyeritz RE, Krogmann ON, Gillessen-kaesbach G, Wakeling EL, Nik-zainal S, Francannet C, Mauran P, Booth C, Barrow M, Dekens R, Loeys BL, Coucke PJ, and De Paepe AM. Arterial tortuosity syndrome: clinical and molecular findings in 12 newly identified families. Hum Mutat 29: 150-158, 2008. 
17. Camarena V and Wang G. The epigenetic role of vitamin C in health and disease. Cell Mol Life Sci 73: 1645-1658, 2016.

18. Campens L, Renard M, Trachet B, Segers P, Muino Mosquera L, De Sutter J, Sakai L, De Paepe A, and De Backer J. Intrinsic cardiomyopathy in Marfan syndrome: results from in-vivo and ex-vivo studies of the Fbn1C1039G/+ model and longitudinal findings in humans. Pediatr Res 78: 256263, 2015.

19. Cartwright MS, Hickling WH, and Roach ES. Ischemic stroke in an adolescent with arterial tortuosity syndrome. Neurology 67: 360-361, 2006.

20. Castori M, Ritelli M, Zoppi N, Molisso L, Chiarelli N, Zaccagna F, Grammatico P, and Colombi M. Adult presentation of arterial tortuosity syndrome in a 51-year-old woman with a novel homozygous c. $1411+1 \mathrm{G}>\mathrm{A}$ mutation in the SLC2A10 gene. Am J Med Genet A 158A: 1164-1169, 2012.

21. Cheng CH, Kikuchi T, Chen YH, Sabbagha NG, Lee YC, Pan HJ, Chang C, and Chen YT. Mutations in the SLC2A10 gene cause arterial abnormalities in mice. Cardiovasc Res 81: 381-388, 2009.

22. Cine N, Basaran M, Guzelmeric F, and Sunar H. Repair of ascending aortic aneurysm in a patient with arterial tortuosity syndrome. Interact Cardiovasc Thorac Surg 12: 1051-1053, 2011.

23. Cook JR, Clayton NP, Carta L, Galatioto J, Chiu E, Smaldone S, Nelson CA, Cheng SH, Wentworth BM, and Ramirez F. Dimorphic effects of transforming growth factor-beta signaling during aortic aneurysm progression in mice suggest a combinatorial therapy for Marfan syndrome. Arterioscler Thromb Vasc Biol 35: 911-917, 2015.

24. Corsico AG, Grosso A, Tripon B, Albicini F, Gini E, Mazzetta A, Di Vincenzo EM, Agnesi ME, Tsana Tegomo E, Ronzoni V, Arbustini E, and Cerveri I. Pulmonary involvement in patients with Marfan Syndrome. Panminerva Med 56: 177-182, 2014.

25. Coucke PJ, Wessels MW, Van Acker P, Gardella R, Barlati S, Willems PJ, Colombi M, and De Paepe A. Homozygosity mapping of a gene for arterial tortuosity syndrome to chromosome 20q13. J Med Genet 40: 747751, 2003.

26. Coucke PJ, Willaert A, Wessels MW, Callewaert B, Zoppi N, De Backer J, Fox JE, Mancini GM, Kambouris M, Gardella R, Facchetti F, Willems PJ, Forsyth R, Dietz HC, Barlati S, Colombi M, Loeys B, and De Paepe A. Mutations in the facilitative glucose transporter GLUT10 alter angiogenesis and cause arterial tortuosity syndrome. Nat Genet 38: 452-457, 2006.

27. Crivellato E, Nico B, and Ribatti D. The chromaffin vesicle: advances in understanding the composition of a versatile, multifunctional secretory organelle. Anat Record (Hoboken, N.J.: 2007) 291: 1587-1602, 2008.

28. Cubero A, Ayala J, Hamzeh G, Cortes A, Udaondo J, and Aramendi JI. Severe arterial tortuosity. World J Pediatr Congenital Heart Surg 8: 231-234, 2017.

29. Cunningham JJ. The glucose/insulin system and vitamin C: implications in insulin-dependent diabetes mellitus. $J$ Am Coll Nutr 17: 105-108, 1998.

30. D'Aniello C, Cermola F, Palamidessi A, Wanderlingh LG, Gagliardi M, Migliaccio A, Varrone F, Casalino L, Matarazzo MR, De Cesare D, Scita G, Patriarca EJ, and Minchiotti G. Collagen prolyl hydroxylation-dependent metabolic perturbation governs epigenetic remodeling and mesenchymal transition in pluripotent and cancer cells. Cancer Res 79: 3235-3250, 2019.

31. Davis JM, Kugler G, and Nixon BP. Nonclostridial cellulitis with subcutaneous emphysema. J Foot Surg 31: 8587, 1992.

32. Dawson PA, Mychaleckyj JC, Fossey SC, Mihic SJ, Craddock AL, and Bowden DW. Sequence and functional analysis of GLUT10: a glucose transporter in the Type 2 diabetes-linked region of chromosome 20q12-13.1. Mol Genet Metab 74: 186-199, 2001.

33. Drera B, Barlati S, and Colombi M. Ischemic stroke in an adolescent with arterial tortuosity syndrome. Neurology 68: 1637; author reply 1637, 2007.

34. Ertugrul A. Diffuse tortuosity and lengthening of the arteries. Circulation 36: 400-407, 1967.

35. Faiyaz-Ul-Haque M, Zaidi SH, Al-Sanna N, Alswaid A, Momenah T, Kaya N, Al-Dayel F, Bouhoaigah I, Saliem M, Tsui LC, and Teebi AS. A novel missense and a recurrent mutation in SLC2A10 gene of patients affected with arterial tortuosity syndrome. Atherosclerosis 203: 466-471, 2009.

36. Fischer-Zirnsak B, Escande-Beillard N, Ganesh J, Tan YX, Al Bughaili M, Lin AE, Sahai I, Bahena P, Reichert SL, Loh A, Wright GD, Liu J, Rahikkala E, Pivnick EK, Choudhri AF, Kruger U, Zemojtel T, van RavenswaaijArts C, Mostafavi R, Stolte-Dijkstra I, Symoens S, Pajunen L, Al-Gazali L, Meierhofer D, Robinson PN, Mundlos S, Villarroel CE, Byers P, Masri A, Robertson SP, Schwarze U, Callewaert B, Reversade B, and Kornak U. Recurrent De Novo Mutations Affecting Residue Arg138 of Pyrroline-5-Carboxylate Synthase Cause a Progeroid Form of Autosomal-Dominant Cutis Laxa. Am J Hum Genet 97: 483-492, 2015.

37. Fischer JW, Kinsella MG, Levkau B, Clowes AW, and Wight TN. Retroviral overexpression of decorin differentially affects the response of arterial smooth muscle cells to growth factors. Arterioscler Thromb Vasc Biol 21: 777-784, 2001.

38. Fortuno A, San Jose G, Moreno MU, Diez J, and Zalba G. Oxidative stress and vascular remodelling. Exp Physiol 90: 457-462, 2005.

39. Franceschini P, Guala A, Licata D, Di Cara G, and Franceschini D. Arterial tortuosity syndrome. Am J Med Genet 91: 141-143, 2000.

40. Gamberucci A, Marcolongo P, Nemeth CE, Zoppi N, Szarka A, Chiarelli N, Hegedus T, Ritelli M, Carini G, Willaert A, Callewaert BL, Coucke PJ, Benedetti A, Margittai E, Fulceri R, Banhegyi G, and Colombi M. GLUT10Lacking in Arterial Tortuosity Syndrome-Is Localized to the Endoplasmic Reticulum of Human Fibroblasts. Int J Mol Sci 18, 2017.

41. Gardella R, Zoppi N, Assanelli D, Muiesan ML, Barlati S, and Colombi M. Exclusion of candidate genes in a family with arterial tortuosity syndrome. Am J Med Genet A 126A: 221-228, 2004.

42. Girard C, Tinel N, Terrenoire C, Romey G, Lazdunski M, and Borsotto M. p11, an annexin II subunit, an auxiliary protein associated with the background $\mathrm{K}+$ channel, TASK1. EMBO J 21: 4439-4448, 2002.

43. Hardin JS, Zarate YA, Callewaert B, Phillips PH, and Warner DB. Ophthalmic findings in patients with arterial tortuosity syndrome and carriers: a case series. Ophthalmic Genet 39: 29-34, 2018.

44. Hasler S, Sturmer J, and Kaufmann C. Keratoglobus and deep stromal corneal opacification in a case of arterial 
tortuosity syndrome. Klin Monbl Augenheilkd 228: 345346, 2011.

45. Heyneke E, Luschin-Ebengreuth N, Krajcer I, Wolkinger $\mathrm{V}$, Muller M, and Zechmann B. Dynamic compartment specific changes in glutathione and ascorbate levels in Arabidopsis plants exposed to different light intensities. BMC Plant Biol 13: 104, 2013.

46. Hoop R, Steinmann B, and Valsangiacomo Buechel ER. Cardiovascular findings in arterial tortuosity syndrome. Eur Heart J 27: 2045, 2006.

47. Ito S, Shen L, Dai Q, Wu SC, Collins LB, Swenberg JA, He $\mathrm{C}$, and Zhang Y. Tet proteins can convert 5-methylcytosine to 5-formylcytosine and 5-carboxylcytosine. Science (New York, N.Y.) 333: 1300-1303, 2011.

48. Joost HG and Thorens B. The extended GLUT-family of sugar/polyol transport facilitators: nomenclature, sequence characteristics, and potential function of its novel members (review). Mol Membr Biol 18: 247-256, 2001.

49. Kalfa D, Gronier C, Ly M, Le Bret E, Roussin R, and Belli E. Giant aortic aneurysm in an infant with arterial tortuosity syndrome. Ann Thorac Surg 94: e51, 2012.

50. Klose RJ, Kallin EM, and Zhang Y. JmjC-domain-containing proteins and histone demethylation. Nat Rev Genet 7: 715727, 2006.

51. Kohli RM and Zhang Y. TET enzymes, TDG and the dynamics of DNA demethylation. Nature 502: 472-479, 2013.

52. Kornmann B, Currie E, Collins SR, Schuldiner M, Nunnari J, Weissman JS, and Walter P. An ER-mitochondria tethering complex revealed by a synthetic biology screen. Science (New York, N.Y.) 325: 477-481, 2009.

53. Lee YC, Huang HY, Chang CJ, Cheng CH, and Chen YT. Mitochondrial GLUT10 facilitates dehydroascorbic acid import and protects cells against oxidative stress: mechanistic insight into arterial tortuosity syndrome. Hum Mol Genet 19: 3721-3733, 2010.

54. Loenarz C and Schofield CJ. Expanding chemical biology of 2-oxoglutarate oxygenases. Nat Chem Biol 4: 152-156, 2008.

55. Loeys BL and Dietz HC. Loeys-Dietz Syndrome. In: GeneReviews $((R))$, edited by Adam MP, Ardinger $\mathrm{HH}$, Pagon RA, Wallace SE, Bean LJH, Stephens K, Amemiya A. Seattle, WA: University of Washington, 1993.

56. MacPherson IS and Murphy ME. Type-2 copper-containing enzymes. Cell Mol Life Sci 64: 2887-2899, 2007.

57. Mandl J, Szarka A, and Banhegyi G. Vitamin C: update on physiology and pharmacology. Br J Pharmacol 157: 10971110, 2009.

58. Massip L, Garand C, Paquet ER, Cogger VC, O'Reilly JN, Tworek L, Hatherell A, Taylor CG, Thorin E, Zahradka P, Le Couteur DG, and Lebel M. Vitamin C restores healthy aging in a mouse model for Werner syndrome. FASEB $J$ 24: 158-172, 2010.

59. May JM. The SLC23 family of ascorbate transporters: ensuring that you get and keep your daily dose of vitamin C. Br J Pharmacol 164: 1793-1801, 2011.

60. McVie-Wylie AJ, Lamson DR, and Chen YT. Molecular cloning of a novel member of the GLUT family of transporters, SLC2a10 (GLUT10), localized on chromosome 20q13.1: a candidate gene for NIDDM susceptibility. Genomics 72: 113-117, 2001.

61. Mizuguchi T, Collod-Beroud G, Akiyama T, Abifadel M, Harada N, Morisaki T, Allard D, Varret M, Claustres M, Morisaki H, Ihara M, Kinoshita A, Yoshiura K, Junien C, Kajii T, Jondeau G, Ohta T, Kishino T, Furukawa Y,
Nakamura Y, Niikawa N, Boileau C, and Matsumoto N. Heterozygous TGFBR2 mutations in Marfan syndrome. Nat Genet 36: 855-860, 2004.

62. Moceri P, Albuisson J, Saint-Faust M, Casagrande F, Giuliano F, Devos C, Benoit P, Hugues N, Ducreux D, Cerboni P, Dageville C, and Jeunemaitre X. Arterial tortuosity syndrome: early diagnosis and association with venous tortuosity. J Am Coll Cardiol 61: 783, 2013.

63. Mueckler M and Thorens B. The SLC2 (GLUT) family of membrane transporters. Mol Aspects Med 34: 121-138, 2013.

64. Munoz-Montesino C, Roa FJ, Pena E, Gonzalez M, Sotomayor K, Inostroza E, Munoz CA, Gonzalez I, Maldonado M, Soliz C, Reyes AM, Vera JC, and Rivas CI. Mitochondrial ascorbic acid transport is mediated by a low-affinity form of the sodium-coupled ascorbic acid transporter-2. Free Radic Biol Med 70: 241-254, 2014.

65. Myllyharju J. Prolyl 4-hydroxylases, key enzymes in the synthesis of collagens and regulation of the response to hypoxia, and their roles as treatment targets. Ann Med 40: 402-417, 2008.

66. Nemeth CE, Marcolongo P, Gamberucci A, Fulceri R, Benedetti A, Zoppi N, Ritelli M, Chiarelli N, Colombi M, Willaert A, Callewaert BL, Coucke PJ, Grof P, Nagy SK, Meszaros T, Banhegyi G, and Margittai E. Glucose transporter type 10-lacking in arterial tortuosity syndromefacilitates dehydroascorbic acid transport. FEBS Lett 590: 1630-1640, 2016.

67. Nemeth CE, Nemoda Z, Low P, Szabo P, Horvath EZ, Willaert A, Boel A, Callewaert BL, Coucke PJ, Colombi M, Banhegyi G, and Margittai E. Decreased nuclear ascorbate accumulation accompanied with altered genomic methylation pattern in fibroblasts from arterial tortuosity syndrome patients. Oxid Med Cell Longev 2019: 8156592, 2019.

68. Nualart FJ, Rivas CI, Montecinos VP, Godoy AS, Guaiquil VH, Golde DW, and Vera JC. Recycling of vitamin C by a bystander effect. J Biol Chem 278: 10128-10133, 2003.

69. Pena E, Roa FJ, Inostroza E, Sotomayor K, Gonzalez M, Gutierrez-Castro FA, Maurin M, Sweet K, Labrousse C, Gatica M, Aylwin CF, Mendoza P, Maldonado M, Delgado C, Madariaga J, Panes J, Silva-Grecchi T, Concha, II, Moraga-Cid G, Reyes AM, Munoz-Montesino C, Vera $\mathrm{JC}$, and Rivas CI. Increased expression of mitochondrial sodium-coupled ascorbic acid transporter-2 (mitSVCT2) as a central feature in breast cancer. Free Radic Biol Med 135: 283-292, 2019.

70. Petris MJ, Mercer JF, Culvenor JG, Lockhart P, Gleeson PA, and Camakaris J. Ligand-regulated transport of the Menkes copper P-type ATPase efflux pump from the Golgi apparatus to the plasma membrane: a novel mechanism of regulated trafficking. EMBO J 15: 6084-6095, 1996.

71. Pletcher BA, Fox JE, Boxer RA, Singh S, Blumenthal D, Cohen T, Brunson S, Tafreshi P, and Kahn E. Four sibs with arterial tortuosity: description and review of the literature. Am J Med Genet 66: 121-128, 1996.

72. Price KD, Price CS, and Reynolds RD. Hyperglycemiainduced latent scurvy and atherosclerosis: the scorbuticmetaplasia hypothesis. Med Hypotheses 46: 119-129, 1996.

73. Price KD, Price CS, and Reynolds RD. Hyperglycemiainduced ascorbic acid deficiency promotes endothelial dys- 
function and the development of atherosclerosis. Atherosclerosis 158: 1-12, 2001.

74. Rebouche CJ. Ascorbic acid and carnitine biosynthesis. Am J Clin Nutr 54: 1147S-1152S, 1991.

75. Renard M, Francis C, Ghosh R, Scott AF, Witmer PD, Ades LC, Andelfinger GU, Arnaud P, Boileau C, Callewaert BL, Guo D, Hanna N, Lindsay ME, Morisaki H, Morisaki T, Pachter N, Robert L, Van Laer L, Dietz HC, Loeys BL, Milewicz DM, and De Backer J. Clinical validity of genes for heritable thoracic aortic aneurysm and dissection. J Am Coll Cardiol 72: 605-615, 2018.

76. Renard M, Holm T, Veith R, Callewaert BL, Ades LC, Baspinar O, Pickart A, Dasouki M, Hoyer J, Rauch A, Trapane P, Earing MG, Coucke PJ, Sakai LY, Dietz HC, De Paepe AM, and Loeys BL. Altered TGFbeta signaling and cardiovascular manifestations in patients with autosomal recessive cutis laxa type I caused by fibulin- 4 deficiency. Eur J Hum Genet 18: 895-901, 2010.

77. Ritelli M, Drera B, Vicchio M, Puppini G, Biban P, Pilati M, Prioli MA, Barlati S, and Colombi M. Arterial tortuosity syndrome in two Italian paediatric patients. Orphanet J Rare Dis 4: 20, 2009.

78. Roa FJ, Pena E, Inostroza E, Sotomayor K, Gonzalez M, Gutierrez-Castro FA, Maurin M, Sweet K, Labrousse C, Gatica M, Aylwin CF, Mendoza P, Maldonado M, Delgado C, Madariaga J, Panes J, Silva-Grecchi T, Concha, II, Moraga-Cid G, Reyes AM, Munoz-Montesino C, Vera JC, and Rivas CI. Data on SVCT2 transporter expression and localization in cancer cell lines and tissues. Data Brief 25: 103972, 2019.

79. Santer R, Schneppenheim R, Dombrowski A, Gotze H, Steinmann B, and Schaub J. Mutations in GLUT2, the gene for the liver-type glucose transporter, in patients with Fanconi-Bickel syndrome. Nat Genet 17: 324-326, 1997.

80. Santoro G, Caianiello G, Rossi G, Farina G, Russo MG, and Calabro R. Hybrid transcatheter-surgical strategy in arterial tortuosity syndrome. Ann Thorac Surg 86: 16821684, 2008.

81. Savini I, Rossi A, Pierro C, Avigliano L, and Catani MV. SVCT1 and SVCT2: key proteins for vitamin C uptake. Amino Acids 34: 347-355, 2008.

82. Segade F. Glucose transporter 10 and arterial tortuosity syndrome: the vitamin C connection. FEBS Lett 584: 2990 2994, 2010.

83. Seidner G, Alvarez MG, Yeh JI, O’Driscoll KR, Klepper J, Stump TS, Wang D, Spinner NB, Birnbaum MJ, and De Vivo DC. GLUT-1 deficiency syndrome caused by haploinsufficiency of the blood-brain barrier hexose carrier. Nat Genet 18: 188-191, 1998.

84. Simon UK, Polanschutz LM, Koffler BE, and Zechmann B. High resolution imaging of temporal and spatial changes of subcellular ascorbate, glutathione and $\mathrm{H}(2) \mathrm{O}(2)$ distribution during Botrytis cinerea infection in Arabidopsis. PLoS One 8: e65811, 2013.

85. Sinnige PF, van Ravenswaaij-Arts CMA, Caruso P, Lin AE, Boon M, Rahikkala E, Callewaert B, and Meiners LC. Imaging in cutis laxa syndrome caused by a dominant negative ALDH18A1 mutation, with hypotheses for intracranial vascular tortuosity and wide perivascular spaces. Eur J Paediatr Neurol 21: 912-920, 2017.

86. Syu YW, Lai HW, Jiang CL, Tsai HY, Lin CC, and Lee YC. GLUT10 maintains the integrity of major arteries through regulation of redox homeostasis and mitochondrial function. Hum Mol Genet 27: 307-321, 2018.
87. Szarka A and Balogh T. In silico aided thoughts on mitochondrial vitamin C transport. J Theor Biol 365: 181189,2015

88. Szarka A and Lorincz T. The role of ascorbate in protein folding. Protoplasma 251: 489-497, 2014.

89. Tanizawa Y, Riggs AC, Chiu KC, Janssen RC, Bell DS, Go RP, Roseman JM, Acton RT, and Permutt MA. Variability of the pancreatic islet beta cell/liver (GLUT 2) glucose transporter gene in NIDDM patients. Diabetologia 37: 420-427, 1994.

90. Tsukada Y, Fang J, Erdjument-Bromage H, Warren ME, Borchers $\mathrm{CH}$, Tempst $\mathrm{P}$, and Zhang Y. Histone demethylation by a family of JMJC domain-containing proteins. Nature 439: 811-816, 2006.

91. Vanakker O, Callewaert B, Malfait F, and Coucke P. The genetics of soft connective tissue disorders. Annu Rev Genomics Hum Genet 16: 229-255, 2015.

92. Vicchio M, Santoro G, Carrozza M, and Caianiello G. Hybrid approach in a case of arterial tortuosity syndrome. Interact Cardiovasc Thorac Surg 7: 736-737, 2008.

93. Wessels MW, Catsman-Berrevoets CE, Mancini GM, Breuning MH, Hoogeboom JJ, Stroink H, Frohn-Mulder I, Coucke PJ, Paepe AD, Niermeijer MF, and Willems PJ. Three new families with arterial tortuosity syndrome. Am J Med Genet A 131: 134-143, 2004.

94. Wight TN and Merrilees MJ. Proteoglycans in atherosclerosis and restenosis: key roles for versican. Circ Res 94: 1158-1167, 2004.

95. Willaert A, Khatri S, Callewaert BL, Coucke PJ, Crosby SD, Lee JG, Davis EC, Shiva S, Tsang M, De Paepe A, and Urban Z. GLUT10 is required for the development of the cardiovascular system and the notochord and connects mitochondrial function to TGFbeta signaling. Hum Mol Genet 21: 1248-1259, 2012.

96. Wood IS, Hunter L, and Trayhurn P. Expression of Class III facilitative glucose transporter genes (GLUT-10 and GLUT-12) in mouse and human adipose tissues. Biochem Biophys Res Commun 308: 43-49, 2003.

97. Wu C, Orozco C, Boyer J, Leglise M, Goodale J, Batalov S, Hodge CL, Haase J, Janes J, Huss JW, 3rd, and Su AI. BioGPS: an extensible and customizable portal for querying and organizing gene annotation resources. Genome Biol 10: R130, 2009.

98. Zaidi SH, Meyer S, Peltekova I, Teebi AS, and FaiyazUl-Haque M. Congenital diaphragmatic abnormalities in arterial tortuosity syndrome patients who carry mutations in the SLC2A10 gene. Clin Genet 75: 588-589, 2009.

99. Zechmann B, Stumpe M, and Mauch F. Immunocytochemical determination of the subcellular distribution of ascorbate in plants. Planta 233: 1-12, 2011.

100. Zito E. PRDX4, an endoplasmic reticulum-localized peroxiredoxin at the crossroads between enzymatic oxidative protein folding and nonenzymatic protein oxidation. Antioxid Redox Signal 18: 1666-1674, 2013.

101. Zito E, Hansen HG, Yeo GS, Fujii J, and Ron D. Endoplasmic reticulum thiol oxidase deficiency leads to ascorbic acid depletion and noncanonical scurvy in mice. Mol Cell 48: 39-51, 2012.

102. Zoppi N, Chiarelli N, Cinquina V, Ritelli M, and Colombi M. GLUT10 deficiency leads to oxidative stress and noncanonical alphavbeta3 integrin-mediated TGFbeta signalling associated with extracellular matrix disarray in 
arterial tortuosity syndrome skin fibroblasts. Hum $\mathrm{Mol}$ Genet 24: 6769-6787, 2015.

103. Zoppi N, Chiarelli N, Ritelli M, and Colombi M. Multifaced Roles of the alphavbeta3 Integrin in Ehlers-Danlos and Arterial Tortuosity Syndromes' Dermal Fibroblasts. Int J Mol Sci 19, 2018.

Address correspondence to: Prof. Bert Callewaert Department of Biomolecular Medicine Center for Medical Genetics Ghent Ghent University

C. Heymanslaan 10 Ghent 9000 Belgium

E-mail: bert.callewaert@ugent.be

Dr. Éva Margittai Institute of Clinical Experimental Research Semmelweis University Tuzolto utca 37-47 Budapest 1094 Hungary

E-mail: margittai.eva@med.semmelweis-univ.hu
Date of first submission to ARS Central, August 7, 2019; date of final revised submission, October 04, 2019; date of acceptance, October 13, 2019.

$\quad$ Abbreviations Used
AA $=$ ascorbic acid
ARCL $=$ autosomal recessive cutis laxa
ALDH $=$ aldehyde dehydrogenase
ATP7A $=$ ATPase copper-transporting alpha
ATS $=$ arterial tortuosity syndrome
DHA $=$ dehydroascorbic acid
ECM $=$ extracellular matrix
$\mathrm{ER}=$ endoplasmic reticulum
GLUT $=$ glucose transporter
LAP $=$ latency-associated peptide
LLC $=$ large latent complex
LPO $=$ lipid peroxidation
NE $=$ nuclear envelope
PPAR $=$ peroxisome proliferator-activated receptor
PUFA $=$ polyunsaturated fatty acid
ROS $=$ reactive oxygen species
SMC $=$ smooth muscle cell
SVCT $=$ sodium-dependent vitamin C transporter
TGF $\beta=$ transforming growth factor beta
TGFBR1/2 $=$ transforming growth factor beta receptor $1 / 2$

